\title{
Bedside Temporary Transvenous Pacemaker Insertion in the Emergency Department: A Single-Center Experience
}

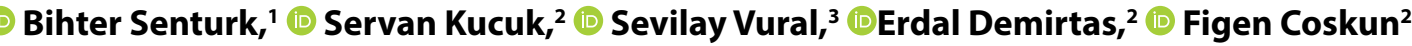 \\ 'Department of Cardiology, Faculty of Medicine, Dokuz Eylul University, Izmir, Turkey \\ ${ }^{2}$ Department of Emergency Medicine, Faculty of Medicine, Dokuz Eylul University, Izmir, Turkey \\ ${ }^{3}$ Department of Emergency Medicine, Faculty of Medicine, Yozgat Bozok University, Yozgat, Turkey
}

\begin{abstract}
Objectives: Insertion of a temporary transvenous pacemaker (TTPM) is one of the life-saving interventions performed in the emergency department (ED). The aim of the study was to determine demographic, clinical characteristics, and in-hospital outcomes of patients who underwent TTPM insertion due to hemodynamically unstable bradyarrhythmia in the ED.

Methods: In our study, 234 consecutive patients who underwent TTPM insertion at the bedside in the ED between January 2014 and October 2019 were included in the study. Etiological characteristics, electrocardiographic (ECG) findings, requirements for permanent pacemaker (PPM), and in-hospital mortality of the patients were analyzed retrospectively.

Results: Extrinsic causes were the most common etiology of unstable bradyarrhythmia (57.6\%). Most extrinsic causes were drug therapy-related factors (60.7\%). Bradyarrhythmia persisted in $60 \%$ of patients after extrinsic causes were eliminated. The most common ECG finding was a high-degree atrioventricular block (62\%). PPM was implanted in $44 \%$ of patients. In-hospital mortality rate was $19.7 \%$. In the multivariate regression analysis, the left ventricular ejection fraction (LVEF) and diastolic blood pressure (DBP) measured at admission ( $p<0.001$ and $p<0.001$, respectively) were determined to be independent predictors for in-hospital mortality.

Conclusion: First diagnosis and intervention in the ED are of great importance for patients with unstable bradyarrhythmia. The fastest possible TTPM insertion in the ED can reduce mortality by reducing the exposure time to hypoperfusion of vital organs, especially in patients with reduced LVEF and low DBP. Furthermore, it should be kept in mind that an underlying latent conduction system disease can also be present in bradyarrhythmias thought to occur potentially due to extrinsic factors.

Keywords: Temporary pacemaker; emergency; bedside; bradyarrhythmia.

Please cite this article as: Senturk B, Kucuk S, Vural S, Demirtas E, Coskun F. Bedside Temporary Transvenous Pacemaker Insertion in the Emergency Department: A Single-Center Experience. Med Bull Sisli Etfal Hosp 2021;55(3):359-365.
\end{abstract}

\section{Introduction}

Insertion of temporary transvenous pacemaker (TTPM) is an essential procedure for patients with impaired hemodynamics, life-threatening bradyarrhythmias and is one of the most common interventions performed in the emergency department (ED). ${ }^{[1]}$ In patients with bradyarrhythmia, a low heart rate gives rise to decreased cardiac output and hypoperfusion of vital organs, which can lead to dizziness, shortness of breath, angina, syncope, acute heart failure, unstable hemodynamic status, and even sudden cardiac

Address for correspondence: Bihter Senturk, MD. Dokuz Eylul University, Faculty of Medicine Department of Cardiology, 35340, Izmir, Turkey Phone: +90 2324124130 E-mail: drbihter@hotmail.com

Submitted Date: March 04, 2021 Accepted Date: April 28, 2021 Available Online Date: September 24,2021

${ }^{\circ}$ Copyright 2021 by The Medical Bulletin of Sisli Etfal Hospital - Available online at www.sislietfaltip.org

OPEN ACCESS This is an open access article under the CC BY-NC license (http://creativecommons.org/licenses/by-nc/4.0/) 
death. ${ }^{[2]}$ Restoring the cardiac depolarization and ensuring effective myocardial contraction by inserting a TTPM provide sufficient cardiac output, and thus end-organ perfusion is maintained. ${ }^{[3,4]}$ Heterogeneous conditions can cause unstable bradyarrhythmias requiring TTPM insertion, such as idiopathic and degenerative diseases of the conduction system,$^{[5]}$ drug overuse and adverse effects, ${ }^{[6-9]}$ electrolyte imbalance, ${ }^{[8,10]}$ and acute myocardial infarction (AMI). ${ }^{[11]}$ The aim of the study was to determine demographic, etiologic, and electrocardiographic (ECG) characteristics of patients who underwent TTPM insertion in the ED and to identify predictors of in-hospital mortality.

\section{Methods}

The Non-invasive Investigation Ethics Committee of Dokuz Eylul University approved this study (date: 13.04.2020, approval number: 2020/07-27). In our study, 234 consecutive patients between January 2014 and October 2019 with hemodynamically unstable bradyarrhythmia treated with insertion of TTPM at the bedside in the ED without using fluoroscopy were included. The patients' data were analyzed retrospectively, the characteristics of the patients, etiologies, ECG findings, echocardiographic, and laboratory data were recorded. In addition, complications during the procedure, whether permanent pacemaker (PPM) was implanted, and in-hospital mortality were noted.

\section{ECG Findings of Patients}

ECG findings of patients were classified as atrioventricular conduction dysfunction (AVCD) and sinoatrial node dysfunction (SAND). AVCD was divided into a high-degree atrioventricular block (HAVB) and atrial fibrillation/flutter with a slow ventricular rate (AF/AFL with SVR). HAVB was comprised of complete AVB ( $3^{\text {rd }}$ degree $A V B$ ) and $2^{\text {nd }}$ degree AVB. SAND consisted of sinus pause and sinus bradycardia.

\section{Etiology of Bradyarrhythmia}

Etiologies of bradyarrhythmia were classified as intrinsic and extrinsic. ${ }^{[12]}$ Intrinsic factors involved idiopathic or degenerative conduction system disease (CSD) and AMI. Extrinsic factors involved drug therapy-related factors and metabolic abnormality-related factors, that is, isolated electrolyte imbalance or combination of electrolyte imbalance and drug therapy. Situations with hyperkalemia medication treatment were defined as potassium $>5.5 \mathrm{~mol} / \mathrm{L}$, while isolated hyperkalemia was defined as potassium $>6 \mathrm{mmol} / \mathrm{L} .{ }^{[13,14]}$

\section{Reversibility of Bradyarrhythmia}

Reversibility of bradyarrhythmia was defined as resolution of bradyarrhythmia following drug discontinuation, treatment of potentially reversible causes (metabolic abnormality and acute myocardial ischemia), and absence of bradyarrhythmia recurrence.

\section{Statistical Analysis}

All statistical procedures were performed with SPSS software (version 25.0, SPSS Inc., Chicago, IL, institutional software). Normality was assessed with the Kolmogorov-Smirnov test. Continuous variables are expressed as mean \pm SD or median $\left(25^{\text {th }}-75^{\text {th }}\right.$ percentile). Categorical variables are presented as number and percentage. The comparison between groups was performed using the independent samples $t$-test for normally distributed continuous variables, the MannWhitney U-test for non-normally distributed continuous variables, and the Chi-square test for categorical variables. Logistic regression analyses were conducted to define predictors of mortality. Variables with $p<0.1$ on univariate analysis were included in logistic regression analysis. $P \leq 0.05$ was considered statistically significant.

\section{Results}

\section{Patient Characteristics}

Two hundred and thirty-four patients were included in this study. About $85 \%$ of patients were the elderly ( $\geq 65$ years). The median age of patients was 78.5 . About $56 \%$ of the patients were women. Most common comorbidities were hypertension (HT) (74.8\%), diabetes mellitus (DM) (37.2\%), and coronary artery disease (CAD) (30.8\%), respectively (Table 1 ).

\section{ECG Findings of Patients}

AVCD was involved in the majority of the cases (73.1\%) followed by SAND (26.9\%). Among AVCDs, HAVB was the most common ECG finding (84.8\%) followed by AF/AFL with SVR (15.2\%). Complete AVB accounted for $86.9 \%$ of HAVB. Among SANDs, sinus pause (79.3\%) represented the majority followed by sinus bradycardia (20.6\%) (Table 1).

\section{Etiology of Bradyarrhythmia}

Extrinsic factors were the most common etiology of bradyarrhythmia (57.6\%). The majority of extrinsic causes were drug therapy-related factors $(60.7 \%)$ (including betablocker $[\mathrm{BB}]$, non-dihydropyridine calcium channel blocker [CCB], digoxin, and amiodarone) followed by metabolic abnormality-related factors (39.3\%). The only electrolyte imbalance determined was hyperkalemia. Hyperkalemia with medication therapy combinations comprised $21.5 \%$ of extrinsic factors, while isolated hyperkalemia comprised $17.8 \%$ of extrinsic factors.

Among drug-induced bradyarrhythmias (DIB), BBs were the most common drugs used (41.5\%), followed by CCBs (19.5\%), digoxin (9.8\%), BB+digoxin (7.3\%), BB+CCB (4.9\%), 
Table 1. Demographic, clinical, and laboratory characteristics of patients $(n=234)$

\begin{tabular}{|c|c|}
\hline Age (years) ${ }^{a}$ & $78.5(69.7-84)$ \\
\hline Gender (female), $n(\%)$ & $131(56 \%)$ \\
\hline Hypertension, $n(\%)$ & $175(74.8 \%)$ \\
\hline Diabetes mellitus, $n(\%)$ & $87(37.2 \%)$ \\
\hline Coronary artery disease, $n(\%)$ & $72(30.8 \%)$ \\
\hline Systolic blood pressure $(\mathrm{mmHg})^{\mathrm{a}}$ & $107(80-132)$ \\
\hline Diastolic blood pressure $(\mathrm{mmHg})^{\mathrm{a}}$ & $65(49-82)$ \\
\hline \multicolumn{2}{|l|}{ Etiology of bradyarrhythmias } \\
\hline I. Extrinsic & $135(57.6 \%)$ \\
\hline a. Drug therapy-related factor & $82(60.7 \%)$ \\
\hline b. Metabolic abnormality-related factor & $53(39.3 \%)$ \\
\hline $\begin{array}{l}\text { - Combination of electrolyte imbalance } \\
\text { and drug therapy }\end{array}$ & $29(21.5 \%)$ \\
\hline - Isolated electrolyte imbalance & $24(17.8 \%)$ \\
\hline II. Intrinsic & 99 (42.3\%) \\
\hline a. Acute myocardial infarction & $50(50.5 \%)$ \\
\hline $\begin{array}{l}\text { b. Idiopathic or degenerative conduction } \\
\text { system disease }\end{array}$ & 49 (49.4\%) \\
\hline \multicolumn{2}{|l|}{ ECG findings of patients, $n(\%)$} \\
\hline I. AVCD & $171(73.1 \%)$ \\
\hline a. HAVB & $145(84.8 \%)$ \\
\hline - Complete AVB & $126(86.9 \%)$ \\
\hline$-2^{\text {nd }}$ degree AVB & $19(13.1 \%)$ \\
\hline b. AF/AFL: With a slow ventricular rate & $26(15.2 \%)$ \\
\hline II. SAND & $63(26.9 \%)$ \\
\hline a. Sinus pause & $50(79.3 \%)$ \\
\hline b. Sinus bradycardia & $13(20.6 \%)$ \\
\hline LVEF (\%) & $50.8 \pm 8.9^{b}$ \\
\hline Sodium $(\mathrm{mmol} / \mathrm{l})^{\mathrm{a}}$ & 137 (134-140) \\
\hline Potassium $(\mathrm{mmol} / \mathrm{l})^{\mathrm{a}}$ & $4.6(4.1-5.4)$ \\
\hline Creatinine $(\mathrm{mg} / \mathrm{dl})^{\mathrm{a}}$ & $1.37(0.98-2.0)$ \\
\hline Hemoglobin $(\mathrm{g} / \mathrm{dl})^{\mathrm{a}}$ & $12.1(10.7-13.7)$ \\
\hline WBC $\left(10^{3} / \mathrm{uL}\right)^{a}$ & $10.4(8-13.5)$ \\
\hline Platelet $\left(10^{3} / \mathrm{uL}\right)^{\mathrm{a}}$ & 205 (166-260) \\
\hline
\end{tabular}

a Median $\left(25^{\text {th }}-75^{\text {th }}\right.$ percentile); ${ }^{\text {Mean }} \pm$ standard deviation. AVCD: Atrioventricular conduction dysfunction; SAND: Sinoatrial node dysfunction; HAVB: High-degree atrioventricular block; AVB:

Atrioventricular block; AF/AFL: Atrial fibrillation/atrial flutter; LVEF: Left ventricular ejection; WBC: White blood cell.

CCB+digoxin (4.9\%), BB+amiodarone (4.9\%), amiodarone (3.7\%), CCB+amiodarone (2.4\%), and BB+CCB+digoxin (1.2\%). Among intrinsic etiologies, AMI and CSD had similar frequency (50.5\% and 49.4\%, respectively) (Table 1). AMI included ST-segment elevation myocardial infarction (STEMI) and acute coronary syndromes without persistent ST segment elevations (NSTE-ACS). Primary percutaneous coronary intervention ( $\mathrm{pPCl}$ ) was performed on all STEMI patients.

About $72 \%$ of AMI patients had inferior STEMI, $26 \%$ had anterior MI, and $2 \%$ had NSTE-ACS. In all the inferior STEMI cases, the culprit lesion was located in the right coronary artery (RCA); in all of the anterior STEMI cases, the culprit lesion was located in the left anterior descending artery (LAD); and in a single patient with NSTE-ACS, the culprit lesion was located in the left main coronary artery, and surgical revascularization was planned. The success rate of primary PCI procedures was $80 \%$ (86.1\% for inferior STEMI and $69.2 \%$ for anterior STEMI). Bradyarrhythmias resolved in $95 \%$ of patients treated with successful pPCI for STEMI.

\section{Complications}

No deaths occurred as a direct result of TTPM insertion. Lead dislocation requiring lead revision with fluoroscopy was observed in $11.1 \%$ of patients. Tamponade resolved by pericardiocentesis occurred in $1.7 \%$ of patients. Pneumothorax that did not require insertion of a chest tube developed in $0.8 \%$ of patients. None of the patients developed complications requiring urgent surgery.

\section{Reversibility of Bradyarrhythmia and PPM Implantation}

Bradyarrhythmia was reversible in $39.3 \%$ of patients. The incidence of reversible bradyarrhythmia was $76 \%$ in AMIassociated bradyarrhythmias (AAB), 45.3\% in metabolic abnormality-induced bradyarrhythmias (MAIB), and 36.6\% in DIB. No reversibility was observed in CSD-associated bradyarrhythmia (CAB) (Table 2). About $27 \%$ of patients with irreversible bradyarrhythmia died before PPM could be implanted. Eventually, PPM was implanted in $44 \%$ of all patients. PPM was implanted in all patients with $C A B, 55 \%$ of those with DIB, and $9 \%$ of those with MAIB. None of the patients with irreversible $A A B$ had PPM implanted because they all died.

The type of PPM was decided according to the guideline. ${ }^{[15]}$ PPM without defibrillator feature was implanted in patients with the left ventricular ejection fraction (LVEF) $>35 \%$ and intracardiac defibrillator (ICD) or cardiac resynchronization therapy-ICD was implanted in those with LVEF $\leq 35 \%$. Types of PPM implanted were DDD-PPM (67.9\%), VVI-PPM (23.3 \%), DDD-ICD (3.9\%), VVI-ICD (0.9\%), and CRT-ICD (3.9\%), respectively (Table 2 ).

\section{In-hospital Mortality}

In-hospital mortality rate was $19.7 \%$. Approximately $11 \%$ of deaths occurred after PPM implantation. Mortality rates 
Table 2. In-hospital outcomes of patients

\begin{tabular}{|c|c|}
\hline $\begin{array}{l}\text { The rate of reversibility for all } \\
\text { bradyarrhythmias }\end{array}$ & $92(39.3 \%)$ \\
\hline \multicolumn{2}{|l|}{$\begin{array}{l}\text { The rate of reversibility in bradyarrhythmias } \\
\text { with different etiologies }\end{array}$} \\
\hline Acute myocardial infarction & $38(76 \%)$ \\
\hline Metabolic abnormality-related factors & $24(45.3 \%)$ \\
\hline Drug therapy-related factors & $30(36.6 \%)$ \\
\hline $\begin{array}{l}\text { Idiopathic or degenerative conduction system } \\
\text { disease }\end{array}$ & 0 \\
\hline Rate of PPM implantation, $n(\%)$ & $103(44 \%)$ \\
\hline \multicolumn{2}{|l|}{ Types of PPM, $n(\%)$} \\
\hline DDD-PPM & $70(67.9 \%)$ \\
\hline VVI-PPM & $24(23.3 \%)$ \\
\hline DDD-ICD & $4(3.9 \%)$ \\
\hline VVI-ICD & $1(0.9 \%)$ \\
\hline CRT-ICD & $4(3.9 \%)$ \\
\hline Rate of in-hospital mortality, $n$ (\%) & $46(19.7 \%)$ \\
\hline \multicolumn{2}{|l|}{$\begin{array}{l}\text { Mortality rates according to different etiological } \\
\text { factors, } n(\%)\end{array}$} \\
\hline Metabolic abnormality-related factors & $23(43.4 \%)$ \\
\hline Acute myocardial infarction & $14(28 \%)$ \\
\hline Drug therapy-related factors & $8(9.8 \%)$ \\
\hline $\begin{array}{l}\text { Degenerative or idiopathic conduction system } \\
\text { disease }\end{array}$ & $1(2 \%)$ \\
\hline
\end{tabular}

PPM: Permanent pacemaker; ICD: Intracardiac defibrillator; CRT: Cardiac resynchronization therapy.

according to different etiologies are presented in Table 2 . Mortality rate was $43.4 \%$ for MAIB, $28 \%$ for AAB, $9.8 \%$ for $\mathrm{DIB}$, and $2 \%$ for $C A B$. The mortality rate in patients with inferior STEMI was $16.6 \%$ and in patients with anterior STEMI was $53.8 \%$. A single patient with NSTE-ACS with a left main coronary artery lesion died before revascularization.

The most common etiologies were extrinsic causes in both survivors and non-survivors $(55.3 \%$ and $67.4 \%$, respectively, $p=0.137)$, and the most common ECG finding was AVCD in both groups $(72.9 \%$ and $73.9 \%$, respectively, $p=1.00$ ) (Table 3).

No significant difference was found between the age and gender of the survivor and the non-survivor groups. The frequencies of HT, DM, CAD, and AMI were similar in non-survivors and survivors. LVEF, hemoglobin level, baseline systolic, and diastolic blood pressure (DBP) were lower in the non-survivor group $(p<0.001, p=0.002, p<0.001$, and $p<0.001$, respectively) (Table 3 ). In the multivariate logistic regression analysis, LVEF and DBP measured at admission to ED ( $p<0.001$ and $p<0.001$, respectively) were determined to be independent predictors of in-hospital mortality (Table 4).

\section{Discussion}

Bradyarrhythmias requiring TTPM are caused by intrinsic and extrinsic factors. While idiopathic or degenerative CSD was in first place among the etiology of bradyarrhythmia in other studies, ${ }^{[16,17]}$ extrinsic factors were the most common etiology in this study. Most extrinsic causes comprised factors related to drug therapy. Since patients were the elderly and had multiple comorbidities, it was not surprising that drug therapy was frequent in our patient group. This is the most important reason for the inclusion of extrinsic etiologies in the first place in our study. Although the frequency of etiologic factors was different, the incidence of PPM implantation was like in this study. ${ }^{[16,17]}$ Bradyarrhythmia persisted in $60 \%$ of patients with extrinsic etiology, although the drugs responsible were discontinued, and hyperkalemia was corrected. In a study examining DIB, it was found that bradyarrhythmia was truly caused by drugs in only $52 \%$ of patients, and about half of patients with DIB needed a PPM. ${ }^{[9]}$ Similarly, PPM was implanted in $55 \%$ of patients with DIB in this study. It was suggested that AVCD usually does not take place without structural heart disease, even if it was triggered by drugs. ${ }^{[7]}$ This situation suggests the presence of a latent CSD in extrinsic etiology. The advanced age of patients also supports the existence of underlying degenerative CSD in extrinsic etiology. Hyperkalemia can also induce bradyarrhythmias in patients with latent CSD. ${ }^{[18]}$ Furthermore, in this study, about $70 \%$ of the patients with hyperkalemia had chronic kidney disease (CKD). CKD can lead to fibrosis and calcification of the cardiac conduction system by disrupting calcium metabolism and cause degenerative CSD. ${ }^{[19]}$ Therefore, bradyarrhythmia can persist, although hyperkalemia was corrected. In addition, in about a fifth of patients with extrinsic etiology, hyperkalemia was accompanied by drug therapy. Situations, where hyperkalemia with the use of AV node blocker medications causes bradyarrhythmia is a new clinical entity called BRASH syndrome. ${ }^{[14]}$ In BRASH syndrome, generally, bradyarrhythmia may develop with lower potassium levels, ${ }^{[13]}$ and bradyarrhythmia is proposed to be due to the synergistic effect between hyperkalemia and medications. ${ }^{[14]}$ This study noted that nearly $45 \%$ of patients with hyperkalemia accompanying drug treatment had potassium levels between 5.5 and 6.0. For this reason, the limit for hyperkalemia combined with drug therapy was lowered.

HAVB was determined to be the most common ECG finding in patients with TTPM. ${ }^{[17,20,21]}$ In addition, HAVB was 
Table 3. Comparison of survivors and non-survivors

\begin{tabular}{|c|c|c|c|}
\hline & Survivor $(n=188)$ & Non-survivors $(n=46)$ & $P$-value \\
\hline Age (years) ${ }^{a}$ & $78(69-84)$ & $79.5(67.7-85)$ & 0.851 \\
\hline Gender (female), $n(\%)$ & 105 (55.9\%) & $26(56.5 \%)$ & 0.935 \\
\hline Hypertension, $n$ (\%) & $142(75.5 \%)$ & $33(71.7 \%)$ & 0.733 \\
\hline Diabetes mellitus, $n$ (\%) & $72(38.3 \%)$ & $15(32.6 \%)$ & 0.474 \\
\hline Coronary artery disease, $n(\%)$ & $55(29.3 \%)$ & $17(37 \%)$ & 0.403 \\
\hline Acute myocardial infarction, $n(\%)$ & $36(19.1 \%)$ & $14(30.4 \%)$ & 0.141 \\
\hline \multicolumn{4}{|l|}{ Etiologies of bradyarrhythmias, $n$ (\%) } \\
\hline Extrinsic & $104(55.3 \%)$ & $31(67.4 \%)$ & 0.137 \\
\hline Intrinsic & $84(44.7 \%)$ & $15(32.6 \%)$ & \\
\hline \multicolumn{4}{|l|}{ ECG findings of patients, $\mathrm{n}(\%)$} \\
\hline AVCD & 137 (72.9\%) & $34(73.9 \%)$ & 1.000 \\
\hline SAND & $51(27.1 \%)$ & $12(26.1 \%)$ & \\
\hline Systolic blood pressure $(\mathrm{mmHg})^{\mathrm{a}}$ & $116(90-137)$ & $86(60-110)$ & $<0.001 *$ \\
\hline Diastolic blood pressure $(\mathrm{mmHg})^{\mathrm{a}}$ & $70(52-82)$ & $50(32-65)$ & $<0.001 *$ \\
\hline $\operatorname{LVEF}(\%)^{\mathrm{b}}$ & $53.2 \pm 6.7$ & $40.8 \pm 9.8$ & $<0.001 *$ \\
\hline Creatinine $(\mathrm{mg} / \mathrm{dl})^{\mathrm{a}}$ & $1.28(0.97-1.92)$ & $1.66(1.04-2.18)$ & 0.066 \\
\hline Sodium $(\mathrm{mmol} / \mathrm{l})^{\mathrm{a}}$ & 137 (134-139) & $137.0(132-140)$ & 0.660 \\
\hline Potassium $(\mathrm{mmol} / \mathrm{l})^{\mathrm{a}}$ & $4.65(4.1-5.21)$ & $4.77(4.1-5.74)$ & 0.466 \\
\hline Hemoglobin $(\mathrm{mg} / \mathrm{dl})^{\mathrm{a}}$ & $12.3(10.9-13.8)$ & $11.4(9.8-12.9)$ & $0.002 *$ \\
\hline WBC $\left(10^{3} / \mathrm{uL}^{\mathrm{a}}\right.$ & $10.3(7.8-13.1)$ & $11.2(8.2-15.0)$ & 0.206 \\
\hline Platelet $\left(10^{3} / \mathrm{uL}\right)^{\mathrm{a}}$ & 207 (171-257) & $196(149-276)$ & 0.486 \\
\hline
\end{tabular}

a Median $\left(25^{\text {th }}-75^{\text {th }}\right.$ percentile); ${ }^{\text {b}}$ Mean \pm standard deviation. ${ }^{*} p<0.05$. ECG: Electrocardiography; TPM: Temporary pacemaker; AVCD: Atrioventricular conduction dysfunction; SAND: Sinoatrial node dysfunction; LVEF: Left ventricular ejection fraction; WBC: White blood cell.

Table 4. Multivariate logistic regression analysis for the predictors of in-hospital mortality

\begin{tabular}{|c|c|c|c|c|}
\hline Variables & Univariate OR (95\% CI) & $P$-value & Multivariate OR (95\% CI) & $P$-value \\
\hline Systolic blood pressure & $0.976(0.965-0.987)$ & $<0.001 *$ & $0.986(0.959-1.013)$ & 0.297 \\
\hline Diastolic blood pressure & $0.960(0.942-0.977)$ & $<0.001 *$ & $0.954(0.931-0.977)$ & $<0.001 *$ \\
\hline LVEF & $0.841(0.801-0.883)$ & $<0.001 *$ & $0.837(0.794-0.883)$ & $<0.001 *$ \\
\hline Creatinine & $1.120(0.885-1.417)$ & 0.346 & - & - \\
\hline Hemoglobin & $0.785(0.645-0.915)$ & $0.002 *$ & $0.906(0.745-1.103)$ & 0.327 \\
\hline
\end{tabular}

found to be the most common type of bradyarrhythmia in patients admitted to the ED due to hemodynamic impairment. ${ }^{[22]}$ In our study, in accordance with these studies, $62 \%$ of the bradyarrhythmias were HAVB. AVCD was observed with a similar frequency in the survivors and non-survivors. In a study investigating the risk factors for mortality in patients with TTPM, like our study, no relationship was found between ECG findings and in-hospital mortality. ${ }^{[21]}$
The frequency and characteristics of unstable bradyarrhythmia in patients with AMI may have changed due to advances in $\mathrm{PCl}$ techniques and treatment strategies. Despite improvements in treatment strategies, AMI can still be complicated by HAVB in patients. ${ }^{[23]}$ AMI did not reach first place in the etiology of bradyarrhythmia requiring TTPM. ${ }^{[16,17]}$ AMI was in third place in this study. However, only patients who underwent TTPM insertion in the ED were included in our study. It should be noted that most 
of the patients with AMI usually undergo TTPM insertion during the $\mathrm{pPCl}$ procedure in the catheter laboratory. Patients with inferior STEMI are at higher risk of HAVB; patients with inferior STEMI have 2- to 4-fold increased risk compared to those with anterior STEMI. ${ }^{[24,25]}$ In accordance with this data, most AMI in our study was inferior AMI. Bradyarrhythmia, in general, occurs as a result of interruption of the perfusion of the AV nodal artery that usually originates from the RCA in inferior STEMI, ${ }^{[26]}$ while generally it usually caused by impaired perfusion of the His-Purkinje system due to occlusion of the septal branches of the LAD in anterior STEMI, an indicator of poor prognosis. The mortality rate is high in anterior STEMI as a result of increased myocardial damage, larger infarct size, and decreased LVEF. ${ }^{[26,27]}$ Concordant with the previous studies, ${ }^{[11,23]}$ in this study, the mortality rate for anterior STEMI was more than 3 times that of inferior STEMI. The need for PPM implantation was significantly different between AMI and non-AMI groups. ${ }^{[20]}$ Bradyarrhythmia is mostly reversible in patients with AMI. ${ }^{[23]}$ In our study, none of the AMI patients with persistent bradyarrhythmia had PPM implanted because these patients died due to $\mathrm{Ml}$ or its complications, while $56 \%$ of the patients in the non-AMI group had PPM implanted.

Complications associated with TTPM insertion are not uncommon. ${ }^{[28]}$ Therefore, TTPM insertion is performed in patients with bradyarrhythmia only if symptoms or signs of hemodynamic impairment are present in our center. TTP placement was safe with relatively low complication rates, although it was performed at the bedside without the usage of fluoroscopy. The low complication rate may be due to the experienced cardiologists performing or supervising the procedures ${ }^{[17,29]}$ and the use of internal jugular vein access in all patients. ${ }^{[30]}$

In-hospital mortality rates of the patients in this study were found to be higher compared to similar studies. ${ }^{[20,31]}$ This situation could be explained by the high number of referrals of elderly patients with multiple comorbidities to our center since it is a tertiary center. The relationship between reduced LVEF and mortality is known in patients who require pacemakers. ${ }^{[32]}$ LVEF was found to be an independent predictor of mortality in our study. Low DBP values are associated with poor prognosis in cardiovascular diseases. Coronary perfusion takes place predominantly in diastole; for this reason, low DBP values can reduce coronary blood flow. It was shown that low DBP values were associated with subclinical myocardial ischemia and major adverse cardiovascular outcomes. ${ }^{[33]}$ Furthermore, Axler ${ }^{[34]}$ reported that low DBP value was the predictor of mortality in patients with cardiogenic shock. In this study, DBP values measured at the time of admission to ED were identified as an independent predictor of in-hospital mortality in patients with bradyarrhythmia requiring TTPM.

\section{Limitations of the Study}

This study has several limitations. The main limitations of our study are its retrospective design, the relatively small number of patients and patients being recruited from a single center. TPM procedures performed within the specified date range were found through the hospital records. Because the procedure was performed urgently and at the bedside, there may be other cases not reported in hospital records. Furthermore, since our center is a tertiary reference center, patients may be more complex than those encountered in real clinical practice. Therefore, multicenter prospective studies with larger numbers of patients are needed.

\section{Conclusion}

We determined several important results in our study. First diagnosis and intervention in the ED are of great importance for patients with unstable bradyarrhythmia. The fastest possible TTPM insertion in the ED can reduce mortality by reducing the exposure time to hypoperfusion of vital organs, especially in patients with reduced LVEF and low DBP at the time of admission to the ED. Furthermore, it should be kept in mind that an underlying latent conduction system disease can also be present in bradyarrhythmias thought to occur potentially due to extrinsic factors.

\section{Disclosures}

Ethics Committee Approval: The research protocol was approved by the Non-invasive Investigation Ethics Committee of Dokuz Eylul University (date: 13.04.2020, approval number: 2020/07-27).

Peer-review: Externally peer-reviewed.

Conflict of Interest: None declared.

Authorship Contributions: Concept - B.S., S.K., S.V., E.D., F.C.; Design - B.S., S.K., S.V., E.D., F.C.; Supervision - B.S., S.K., S.V., E.D., F.C.; Materials - B.S., S.K., F.C.; Data collection and/or processing - B.S., S.K., F.C.; Analysis and/or interpretation - B.S., S.K., E.D., F.C.; Literature search - B.S., S.K., S.V., F.C.; Writing - B.S., E.D., F.C.; Critical review - B.S., S.K., S.V., E.D., F.C.

\section{References}

1. Kaushik V, Leon AR, Forrester JS Jr, Trohman RG. Bradyarrhythmias, temporary and permanent pacing. Crit Care Med 2000;28:N121-8. [CrossRef]

2. Dreifus LS, Michelson EL, Kaplinsky E. Bradyarrhythmias: clinical significance and management. J Am Coll Cardiol 1983;1:327-38. [CrossRef]

3. Furman S, Schwedel JB. An intracardiac pacemaker for StokesAdams seizures. N Engl J Med 1959;261:943-8. [CrossRef] 
4. Nasuhoğlu A. Suni pace-maker'le tedavi edilen bir tam blok vak'ası. Sisli Etfal Hastan Tip Bul 1973;7:168-70.

5. Adán V, Crown LA. Diagnosis and treatment of sick sinus syndrome. Am Fam Physician 2003;67:1725-32.

6. Türk HŞ, Totoz T, Çınar S, Idi I, Oba S. Diltiazem over dose: case report. Sisli Etfal Hastan Tip Bul 2010;44:41-4.

7. Knudsen MB, Thøgersen AM, Hjortshøj SP, Riahi S. The impact of drug discontinuation in patients treated with temporary pacemaker due to atrioventricular block. J Cardiovasc Electrophysiol 2013;24:1255-8. [CrossRef]

8. Duarte T, Gonçalves S, Sá C, Marinheiro R, Fonseca M, Farinha $\mathrm{J}$, et al. Permanent cardiac pacing for patients with iatrogenic or potentially reversible bradyarrhythmia. Rev Port Cardiol (Engl Ed) 2019;38:105-11. [CrossRef]

9. Osmonov D, Erdinler I, Ozcan KS, Altay S, Turkkan C, Yildirim E, et al. Management of patients with drug-induced atrioventricular block. Pacing Clin Electrophysiol 2012;35:804-10. [CrossRef]

10. Vuckovic K, Richlin D. Bradycardia induced by hyperkalemia. AAOHN J 2004;52:186-7. [CrossRef]

11. Harikrishnan P, Gupta T, Palaniswamy C, Kolte D, Khera S, Mujib M, et al. Complete heart block complicating ST-segment elevation myocardial infarction: temporal trends and association with in-hospital outcomes. JACC Clin Electrophysiol 2015;1:529-38. [CrossRef]

12. Mangrum JM, DiMarco JP. The evaluation and management of bradycardia. N Engl J Med 2000;342:703-9. [CrossRef]

13. Bonvini RF, Hendiri T, Anwar A. Sinus arrest and moderate hyperkalemia. Ann Cardiol Angeiol (Paris) 2006;55:161-3. [CrossRef]

14. Farkas JD, Long B, Koyfman A, Menson K. BRASH Syndrome: Bradycardia, renal failure, AV blockade, shock, and hyperkalemia. J Emerg Med 2020;59:216-23. [CrossRef]

15. Ponikowski P, Voors AA, Anker SD, Bueno H, Cleland JGF, Coats AJS, et al; ESC Scientific Document Group. 2016 ESC Guidelines for the diagnosis and treatment of acute and chronic heart failure:TheTask Force for the diagnosis and treatment of acute and chronic heart failure of the European Society of Cardiology (ESC)Developed with the special contribution of the Heart Failure Association (HFA) of the ESC. Eur Heart J 2016;37:2129-200. [CrossRef]

16. Jou YL, Hsu HP, Tuan TC, Wang KL, Lin YJ, Lo LW, et al. Trends of temporary pacemaker implant and underlying disease substrate. Pacing Clin Electrophysiol 2010;33:1475-84. [CrossRef]

17. BjørnstadCC,GjertsenE,ThorupF,GundersenT,TobiassonK,Otterstad JE. Temporary cardiac pacemaker treatment in five Norwegian regional hospitals. Scand Cardiovasc J 2012;46:137-43. [CrossRef]

18. Mehta NJ, Chhabra VK, Khan IA. Sinus arrest or sinoventricular conduction in mild hyperkalemia.J Emerg Med 2001;20:163-4. [CrossRef]

19. Ferrari F, Nascimento P Jr, Vianna PT. Complete atrioventricular block during renal transplantation in a patient with Alport's syndrome: case report. Sao Paulo Med J 2001;119:184-6. [CrossRef]

20. López Ayerbe J, Villuendas Sabaté R, García García C, Rodríguez Leor O, Gómez Pérez M, Curós Abadal A, et al. Temporary pacemakers: current use and complications. [Article in Spanish]. Rev Esp Cardiol 2004;57:1045-52. [CrossRef]

21. Dawood FZ, Boerkircher A, Rubery B, Hire D, Soliman EZ. Risk of early mortality after placement of a temporary-permanent pacemaker. J Electrocardiol 2016;49:530-5. [CrossRef]
22. Sodeck GH, Domanovits H, Meron G, Rauscha F, Losert H, Thalmann $M$, et al. Compromising bradycardia: management in the emergency department. Resuscitation 2007;73:96-102. [CrossRef]

23. Gang UJ, Hvelplund A, Pedersen S, Iversen A, Jøns C, Abildstrøm SZ, et al. High-degree atrioventricular block complicating ST-segment elevation myocardial infarction in the era of primary percutaneous coronary intervention. Europace 2012;14:1639-45. [CrossRef]

24. Aplin M, Engstrøm T, Vejlstrup NG, Clemmensen P,Torp-Pedersen C, Køber L; TRACE Study Group. Prognostic importance of complete atrioventricular block complicating acute myocardial infarction. Am J Cardiol 2003;92:853-6. [CrossRef]

25. Goldberg RJ, Zevallos JC, Yarzebski J, Alpert JS, Gore JM, Chen Z, et al. Prognosis of acute myocardial infarction complicated by complete heart block (the Worcester Heart Attack Study). Am J Cardiol 1992;69:1135-41. [CrossRef]

26. Sutton R, Davies M. The conduction system in acute myocardial infarction complicated by heart block. Circulation 1968;38:98792. [CrossRef]

27. Tans AC, Lie KI, Durrer D. Clinical setting and prognostic significance of high degree atrioventricular block in acute inferior myocardial infarction: a study of 144 patients. Am Heart J 1980;99:4-8. [CrossRef]

28. Brignole M, Auricchio A, Baron-Esquivias G, Bordachar P, Boriani G, Breithardt OA, et al. 2013 ESC Guidelines on cardiac pacing and cardiac resynchronization therapy: the Task Force on cardiac pacing and resynchronization therapy of the European Society of Cardiology (ESC). Developed in collaboration with the European Heart Rhythm Association (EHRA). Eur Heart J 2013;34:2281-329. [CrossRef]

29. BettsTR. Regional survey of temporary transvenous pacing procedures and complications. Postgrad Med J 2003;79:463-5. [CrossRef]

30. Parienti JJ, Mongardon N, Mégarbane B, Mira JP, Kalfon P, Gros A, et al; 3SITES Study Group. Intravascular Complications of Central Venous Catheterization by Insertion Site. N Engl J Med 2015;373:1220-9. [CrossRef]

31. Ng ACC, Lau JK, Chow V, Adikari D, Brieger D, Kritharides L. Outcomes of 4838 patients requiring temporary transvenous cardiac pacing: A statewide cohort study. Int J Cardiol 2018;271:98-104. [CrossRef]

32. Mazza A, Bendini MG, Leggio M, Riva U, Ciardiello C, Valsecchi S, et al. Incidence and predictors of heart failure hospitalization and death in permanent pacemaker patients: a single-centre experience over medium-term follow-up. Europace 2013;15:1267-72. [CrossRef]

33. McEvoy JW, Chen Y, Rawlings A, Hoogeveen RC, Ballantyne CM, Blumenthal RS, et al. Diastolic blood pressure, subclinical myocardial damage, and cardiac events: implications for blood pressure control. J Am Coll Cardiol 2016;68:1713-22. [CrossRef]

34. Axler O. Low diastolic blood pressure as best predictor of mortality in cardiogenic shock*. Crit Care Med 2013;41:2644-7. [CrossRef] 